\title{
Biopsychosocial Impact of Voicing and General Coping Style in Teachers
}

\author{
A. Van Wijck-Warnaar ${ }^{\text {a }}$ M.J.M.C. Van Opstal' ${ }^{c}$ K. Exelmans $^{d}$ K. Schaekers ${ }^{d}$ \\ G. Thomas ${ }^{\text {b F.I.C.R.S. de Jong }}{ }^{\mathrm{e}, \mathrm{f}}$ \\ ${ }^{a}$ Department of ENT, Bernhoven Ziekenhuis, Veghel, and ${ }^{b}$ Department of ORL, University Medical Centre \\ St. Radboud, Nijmegen, The Netherlands; 'Practice for Vocal Communication and Word Performance Arts, \\ dSpeech Therapy and Audiology Sciences, e Department of ENT-Head and Neck Surgery, University Hospital K.U. \\ Leuven, and ${ }^{\mathrm{f} C e n t r e}$ of Excellence for Voice, Lab. Exp. ORL, K.U. Leuven, Belgium
}

\section{Key Words}

Voice handicap $\cdot$ Coping style $\cdot$ Teachers $\cdot$ Stress

\begin{abstract}
Objective: The aim of the study was to explore the general coping style of female teachers with a relatively low voice handicap compared with teachers with a relatively high voice handicap. Patients and Methods: A cross-sectional questionnaire survey was conducted among 450 teachers using the Voice Handicap Index (VHI) and the Utrecht Coping List (UCL). A group of 400 subjects quasi-randomly selected from the general population were used as controls. Results: Teachers with a relatively high voice handicap (VHI $\geq 75$ th percentile) scored lower on the UCL subscale 'active confrontation or dealing with the problem' $(p=0.001)$ and higher on the UCL subscale 'passive reaction pattern' $(p=$ 0.006), compared to teachers with a relatively low voice handicap ( $\mathrm{VHI} \leq 25$ th percentile). Among the general population, it was found that subjects with a relatively high voice handicap scored higher on the UCL subscales 'avoidance/ waiting' $(p=0.001)$ and 'passive reaction pattern' $(p<0.001)$ than those with a relatively low voice handicap. From the groups with a relatively high total VHI score, the teachers scored higher on the scale 'seeking for social support' than
\end{abstract}

the general population $(p=0.022)$. However, this had already been found in the total groups. The general population scored higher than the teachers on the subscale 'avoidance/ waiting' $(p=0.027)$. There was no significant difference on the other subscales of the UCL. Conclusion: The coping style of the teachers with a relatively high $\mathrm{VHI}$ score may lead to less optimal problem solving possibilities and consequently increased vulnerability, problems and less psychosomatic well-being. Training coping strategies in the curriculum of student teachers may contribute to their response when they experience voice problems during their teaching career. With a view to self-efficacy, adequate coping strategies need to be taught to teachers.

Copyright $\odot 2010$ S. Karger AG, Basel

\section{Introduction}

Teachers have been found to form a large proportion of professional voice users [1-4] and they have an increased risk for developing voice problems during their careers [4-6]. In this context, teachers have appeared to be more vulnerable to voice problems than other professional voice users [5-8]. The impact of a voice problem is linked to the manner in which the individual reacts to his

\section{KARGER}

Fax +4161306 1234

E-Mail karger@karger.ch

www.karger.com
C) 2010 S. Karger AG, Basel

1021-7762/10/0622-0040\$26.00/0

Accessible online at:

www.karger.com/fpl
F.I.C.R.S. de Jong

Department of ENT-Head and Neck Surgery, University Hospital K.U. Leuven Kapucijnenvoer 33

BE-3000 Leuven (Belgium)

Tel. +32 163323 28, E-Mail felix.dejong@med.kuleuven.be 
voice problems [5, 9]. Schreurs and van de Willege [10] described coping as the way an individual responds behaviorally, cognitively and emotionally to circumstances that demand actual adjustment and adjustment of chronic problems. Therefore, coping influences mental, physical and social wellness. An adequately adapted style of coping with events of life has been found to help in managing health and prevention of problems and reinforces self-confidence. It has been observed that the vulnerability to an illness is influenced by the individual's style of coping with the stressors of life [10]. On the other hand, the course of an illness depends highly on the way the individual reacts on the illness. Adequately adapted coping with an illness prevents worsening of the illness and promotes recovery and makes it easier to handle $[10,11]$.

Coping in general is linked to the onset and the development of a voice problem. Communicational needs are part of life and require specific coping. Adapted voicing is a specific coping skill to meet needs in various communication situations. The demands of the teacher's profession require a high level of vocal skills, in order to obtain adaptation to the desired vocal communication [12, 13].

Voice problems are experienced as a handicap and can be detrimental to the teacher's career. Therefore, it is important to investigate the general coping style of teachers as a mediator in biopsychosocial conditions of voicing and voice problems. The aim of the pertinent study is to explore the general coping style of female teachers who report a relatively low voice handicap compared with teachers who report a relatively high voice handicap.

\section{Methods}

The study was carried out in the region of Flanders in Belgium. Questionnaires were sent to primary schools and distributed among 450 female teachers. Quasi-randomly, as a sample of convenience, 400 questionnaires were distributed to females in the general population, who served as controls. Only females were studied in this study because female teachers report significantly more voice problems than male teachers and may have a different coping style $[2,8]$.

\section{Questionnaires}

The voice handicap was assessed by the Dutch version of the Voice Handicap Index (VHI) $[9,14]$. The VHI has been found to estimate the biopsychosocial impact of voicing and voice problems. It consists of 30 questions that are grouped into functional, emotional and physical subscales. Each subscale consists of 10 questions. The participants were asked to respond to the questions on a 5-point ordinal scale. They had to mark the degree to which they agreed or disagreed to statements in the question-

Biopsychosocial Impact of Voicing and

General Coping Style in Teachers naire: never $(=0)$, almost never $(=1)$, sometimes $(=2)$, nearly always $(=3)$ and always $(=4)$. Consequently, the scores of the total $\mathrm{VHI}$ are between 0 and 120 .

The general coping style was assessed by the Utrecht Coping List (UCL). The UCL consists of 47 questions and the responses are given on a 4-point ordinal scale. The possible answers are: seldom or never $(=1)$, sometimes $(=2)$, often $(=3)$, and very often $(=$ 4). The UCL consists of subscales, along 7 categories: 'active confrontation or dealing with the problem' (7 items), 'avoidance/ waiting' (8 items), 'passive reaction pattern' (7 items), 'reassuring thoughts' (5 items), 'palliative reactions' (8 items), 'emotional expression' (3 items), and 'seeking for social support' (6 items). Three items were not included in 1 of the 7 categories [10].

\section{Groups of Interest}

Subjects who scored in the highest (VHI $\geq 75$ th percentile) and lowest quartiles (VHI $\leq 25$ th percentile) of the VHI were selected for analysis. The upper quartile scores were considered to indicate a relatively high voice handicap, compared to the lower quartile.

\section{Statistics}

The data were analyzed using the statistics program SPSS 16.0. The one-sample, 2-tailed Kolmogorov-Smirnov test was used to examine whether continuous variables were normally distributed. For continuous variables that were non-normally distributed, the Mann-Whitney $U$ test was used. The significance value was set at $\mathrm{p} \leq 0.05$.

\section{Results}

The response rate was $51 \%$ for the teachers $(\mathrm{n}=230)$ and $60 \%(\mathrm{n}=240)$ for the control group. The mean age of the teachers was 36.3 years (range 21-60) and 40.4 years (range 21-59) for the controls.

\section{Teachers}

Compared to teachers with a relatively low voice handicap $(n=56)$, teachers with a relatively high voice handicap $(n=54)$ scored lower on the UCL subscale 'active confrontation or dealing with the problem' $(p=0.001)$ and higher on the UCL subscale 'passive reaction pattern' $(\mathrm{p}=0.001)$ (table 1). There was no significant difference observed for the other subscales of the UCL.

\section{The General Population}

In the general population, it was found that subjects reporting a relatively high voice handicap $(n=72)$ scored higher on the UCL subscales 'avoidance/waiting' ( $\mathrm{p}<$ $0.001)$ and 'passive reaction pattern' $(\mathrm{p}<0.001)$ than those reporting a relatively low voice handicap $(n=73)$ (table 2). There was no significant difference in the other subscales of the UCL. 
Table 1. The scores on the UCL subscales of the teachers with a relatively low $(\mathrm{n}=56)$ and high $(\mathrm{n}=54)$ total VHI score

\begin{tabular}{llll}
\hline UCL subscale & VHI score & Median & $\mathrm{p}$ \\
\hline ACT & low & $19.0(3.00)$ & 0.001 \\
& high & $16.0(4.25)$ & \\
\hline AV-W & low & $15.0(3.00)$ & 0.213 \\
& high & $15.0(4.00)$ & \\
\hline PAS & low & $10.0(3.00)$ & 0.001 \\
& high & $12.0(5.00)$ & \\
\hline REAS & low & $13.0(3.75)$ & 0.455 \\
& high & $13.0(3.00)$ & \\
\hline PAL & low & $16.0(5.75)$ & 0.808 \\
& high & $16.0(3.00)$ & \\
\hline EXP & low & $6.0(1.75)$ & 0.813 \\
\hline SOC & high & $6.0(2.00)$ & \\
& low & $16.0(4.75)$ & 0.931 \\
& high & $15.0(6.00)$ & \\
\hline
\end{tabular}

$\mathrm{ACT}=$ Active confrontation or dealing with the problem; AV$\mathrm{W}=$ avoidance/waiting; PAS = passive reaction pattern; REAS = reassuring thoughts; $\mathrm{PAL}=$ palliative reactions; $\mathrm{EXP}=$ emotional expression; SOC $=$ seeking for social support; VHI score low = $\mathrm{VHI} \leq 25$ th percentile; VHI score high $=\mathrm{VHI} \geq 75$ th percentile. The figures in parentheses indicate the interquartile range. The level of significance (p) is calculated by the Mann-Whitney $U$ test.

\section{Comparison of Coping of Teachers and the General Population}

In total the responses of 213 teachers and of $238 \mathrm{sub}-$ jects from the general population were analyzed. The teachers scored significantly higher $(\mathrm{p}=0.001)$ on the subscale 'seeking for social support' than the general population, irrespective of their voice handicap. No significant difference was observed for the other subscales of the UCL.

Comparison of Coping of Teachers and Controls Both Reporting a Relatively High Voice Handicap

From the groups with a relatively high total VHI score, the teachers $(n=54)$ scored higher on the scale of 'seeking for social support' than the general population $(\mathrm{n}=$ $62)(p=0.022)$ (table 3$)$. The general population $(n=62)$ scored higher than the teachers $(\mathrm{n}=54)$ on the subscale 'avoidance/waiting' ( $\mathrm{p}=0.027)$. No significant difference was observed for the other scales of the UCL.
Table 2. The scores on the UCL subscales of the general population with a relatively low $(n=73)$ and high $(n=72)$ total VHI score

\begin{tabular}{llll}
\hline UCL subscale & VHI score & Median & $\mathrm{p}$ \\
\hline ACT & low & $18.0(4.00)$ & 0.091 \\
& high & $16.0(5.00)$ & \\
\hline AV-W & low & $15.0(3.50)$ & $<0.001$ \\
& high & $16.0(3.00)$ & \\
\hline PAS & low & $11.0(4.00)$ & $<0.001$ \\
& high & $13.0(4.25)$ & \\
\hline REAS & low & $12.0(3.50)$ & 0.915 \\
& high & $12.0(5.00)$ & \\
\hline PAL & low & $16.0(5.00)$ & 0.327 \\
& high & $17.0(4.00)$ & \\
\hline EXP & low & $6.0(2.00)$ & 0.753 \\
& high & $6.0(2.00)$ & \\
\hline SOC & low & $15.0(5.00)$ & 0.126 \\
& high & $13.0(5.25)$ & \\
\hline
\end{tabular}

$\mathrm{ACT}=$ Active confrontation or dealing with the problem; AV$\mathrm{W}=$ avoidance/waiting; $\mathrm{PAS}=$ passive reaction pattern; $\mathrm{REAS}=$ reassuring thoughts; $\mathrm{PAL}=$ palliative reactions; $\mathrm{EXP}=$ emotional expression; SOC $=$ seeking for social support; VHI score low $=$ $\mathrm{VHI} \leq 25$ th percentile; VHI score high $=$ VHI $\geq 75$ th percentile. The figures in parentheses indicate the interquartile range. The level of significance (p) is calculated by the Mann-Whitney U test.

\section{Discussion}

In reaction to the dynamics of circumstances and events of life the interpretation of a situation (appraisal) can be differentiated from the way to handle the situation (coping). Appraisal is a cognitive process, basic to the evaluation of a situation. A situation can be interpreted as not stressful or stressful. A stressful situation is evaluated as harmful, as a threat or as a challenge $[10,12]$. The VHI could be considered as an operational equivalent of appraisal and evaluation of actual voicing situations. The VHI score assesses voice handicap, i.e. self-reported biopsychosocial impact of the voice. The VHI is designed in order to assess the handicap that the voice causes to the person in the emotional, physical and functional domains. These domains are part of the stress circle that consists of stressor/signal-arousal/activation-emotioncoping-effects, and is called SAECE $[12,13]$. The effects in the SAECE circle are organic, social and existential 
Table 3. The scores on the UCL subscales of the teachers $(n=54)$ and the general population $(n=62)$, both with a relatively high total VHI score (VHI $\geq 75$ th percentile)

\begin{tabular}{llll}
\hline UCL subscale & Group & Median & $\mathrm{p}$ \\
\hline ACT & teachers & $16.0(4.25)$ & 0.843 \\
& controls & $16.0(5.00)$ & \\
\hline AV-W & teachers & $15.0(4.00)$ & 0.027 \\
& controls & $16.0(3.00)$ & \\
\hline PAS & teachers & $12.0(5.00)$ & 0.202 \\
& controls & $13.0(4.25)$ & \\
\hline REAS & teachers & $13.0(3.00)$ & 0.238 \\
& controls & $12.0(4.00)$ & \\
\hline PAL & teachers & $16.0(3.00)$ & 0.432 \\
& controls & $17.0(4.00)$ & \\
\hline EXP & teachers & $6.0(2.00)$ & 0.701 \\
& controls & $6.0(2.00)$ & \\
\hline SOC & teachers & $15.0(6.00)$ & 0.022 \\
& controls & $13.0(5.25)$ & \\
\hline
\end{tabular}

$\mathrm{ACT}=$ Active confrontation or dealing with the problem; AV$\mathrm{W}=$ avoidance/waiting; PAS = passive reaction pattern; REAS = reassuring thoughts; $\mathrm{PAL}=$ palliative reactions; $\mathrm{EXP}=$ emotional expression; $\mathrm{SOC}=$ seeking for social support. The figures in parentheses indicate the interquartile range. The level of significance (p) is calculated by the Mann-Whitney $U$ test.

well-being in general and in specific communication needs. These effects are elements in the determination of the apprehension of the stressor/signal in the SAECE circle. Appraisal defines stressor/signal as an eustressor or a distressor. The way situations of vocal communication are apprehended is a consequence of the effects of vocal communication in daily life and in professional situations. A high voice handicap could be called a distressor in the apprehension of voicing stimuli. The VHI score is an indication of the subject's overall evaluation of stressors related to some aspects of voicing. The physical subscale of the VHI refers to the organic functioning, the functional subscale to the effects on social well-being and the emotional subscale to aspects of emotion and arousal/ activation. The impact of a voice (problem) is linked to the subjective experience of effects of the actual voicing, that may be either euvoicing or disvoicing [13].

Coping in terms of the SAECE circle is the competence to handle stressor/signal, arousal/activation and emotion. In this view, voice handicap and coping are con- nected with each other in the stress circle. This connection follows the vision of functional relationships between stress and voice. In this vision, eustress and euvoicing may be related to adequate modes of coping in general and to adapted modes of voicing when coping with communication needs. The onset and the development of a voice problem is linked to the way of coping in general as a part of the way of life. Voicing is a tool to meet specific communication needs [13]. Consequently, adequate coping will result in low handicap, i.e. low VHI scores. Disvoicing may be related to inadequate modes of coping in general and to nonadapted modes of voicing when coping with communication needs. Consequently, inadequate coping will result in high handicap, i.e. high VHI scores.

In the concept of stress-voicing interrelations, coping refers to general modes of coping, as well as specific vocal modes of coping. Until now, however, there is no validated questionnaire to assess specific (vocal) modes of coping. This raises the question what is the role of a general coping style of teachers in self-reported biopsychosocial impact of voicing? The UCL questionnaire connects general coping style with the stress circle in several aspects (table 4).

Apart from differentiating the two factors which have resulted from factor analysis, it remains important to keep an eye on the diversity of coping strategies and to measure them separately [10].

The UCL originates from the idea that individuals prefer specific modes and combinations of modes of coping in various and different situations, called coping style. The capacity for a flexible use and combination of different modes of coping in various and different situations prevents one-sided stereotypy and enhances effective functioning, that decreases handicap. It should be stressed that distinct methods of coping are not good or bad per se. The application and effects of a particular coping mode depend not only on aspects of the problem, but on qualities and capacities of the person as well. It is important that the methods of coping be adequate when applied to the specific situation. In other words, the coping style is adapted to the problem. For example, if the situation cannot be changed, it is probably better to apply cognitive restructuring, reassuring, avoiding or palliative modes of coping, instead of persisting in endeavors to handle the problem actively. The effectiveness of a particular coping style depends on several dimensions of the situation and events such as duration, frequency, intensity, predictability, and being manageable. In the long term (1 year), the habitual coping styles of a 'passive reaction pattern' and 
Table 4. The UCL questionnaire relating general coping style with the stress circle

\begin{tabular}{lll}
\hline Factor & Orientation & UCL subscale \\
\hline $\begin{array}{ll}\text { Factor 1: reactive, } \\
\text { defensive }\end{array}$ & 1a Situation oriented & $\begin{array}{l}\text { AV-W: avoidance/waiting } \\
\text { PAS: passive reaction pattern }\end{array}$ \\
\hline $\begin{array}{l}\text { 1b Tension oriented } \\
\text { Factor 2: active, }\end{array}$ & 2a Situation oriented & $\begin{array}{l}\text { ACT: confrontation or dealing with the } \\
\text { problem actively }\end{array}$ \\
\hline $\begin{array}{l}\text { Factor 3: used in } \\
\text { factors 1 and 2 }\end{array}$ & Mixed oriented & REAS: reassuring thoughts \\
\hline
\end{tabular}

'avoidance/waiting' facilitate a decrease of self-confidence, negative affect and the onset of psychic complaints. The habitual coping styles of 'confrontation or dealing with the problem actively' and 'seeking for social support' facilitate increased self-confidence and positive affect [10]. Personal characteristics such as motivation, skills and having the disposal over resources are important variables in the probability that determines if a particular coping mode is applied. The interaction of personal characteristics, the dimensions of stressful events and aspects of the social environment relate to the effects of coping [10].

The aim of the pertinent study is to explore the general coping style of female teachers who report a relatively low voice handicap compared with teachers who report a relatively high voice handicap. It can be considered that those with VHI scores in the highest quartile and the lowest quartile of the VHI score range reflect a relatively severe and relatively minor voice handicap, respectively. A second question was whether the general coping style of teachers is different from that of the general population.

Both teachers and controls with a relatively high voice handicap show a more passive reaction pattern. This means that they are inclined to cope in a situation-oriented way, while they are absorbed in the situation in a pessimistic and worrying manner. They feel helpless in handling the situation and ruminate about the past. This indicates a defensive approach. Moreover, the teachers with a relatively high voice handicap score have lower scores on the subscale 'active confrontation or dealing with the problem'. This can mean that they have a lack of possibility to handle problems in a relaxed way from different perspectives, to arrange things in a logic manner, to act purposely and self-confidently in problem solving. The passive reaction pattern facilitates the decrease of self-confidence and the lack of confrontation with the problem and active handling. It prevents reinforcement of self-confidence. In the long term, in teachers with a relatively high voice handicap the combination of the inclinement to a defensive mode of coping and the declinement to an offensive mode of coping would result in a lower self-esteem when compared to their colleagues with a relatively minor voice handicap.

De Jong et al. [15] examined the maintaining factors and coping strategies in 76 teachers with persisting voice problems. They assessed physical, functional, psychological and socioeconomic factors. In their study, they drew a parallel with the psychological cascade model described by Anderson [16] in patients with chronic spinal pain. This cascade model consists of three phases. In the first phase, the patient experiences the disorder as a threat. This phase is characterized by anxiety, fear and terror of loss, struggle against the loss, searching for help, exhaustion and isolation, and depression. The patient might leave the first phase to enter the second phase of the cascade model if the influence of the maintaining factors is not too high and coping style is adequate. The second phase is called 'the pit' and is characterized by surrender to the loss and giving in without giving up, which is followed by clarity and acceptance of the disorder. Subsequently, the patient can proceed into the third phase of renewal, which is characterized by hope. This phase may finally lead to recovery. The majority of the teachers were found to be in the deadlocked situation called phase 1 of the cascade model. The combination of externalization and unawareness of the situation proved to be the main risk factor. Subjective rating of the voice problem was assessed by the VHI and a visual analogue scale. Teachers in phase 1 of the cascade model showed higher VHI and visual analogue scale scores compared to the teachers that were not in phase 1 . If this psychological cascade 
model is applied to the results of the pertinent study, the teachers with a relatively high voice handicap are at risk to be in the deadlocked phase 1 , which increases vulnerability, hinders adequate solving of the problem, increases handicap and consequent reduction of quality of life [17].

In the context of relatively high voice handicap scores versus low voice handicap scores, one coping mode of the controls is similar to that of the teachers. The controls with high handicap also showed higher scores on the subscale 'passive reaction pattern'. In contradistinction to the teachers, the controls with a relatively high handicap showed higher scores on the subscale 'avoidance/waiting. They let things run, keep away from situations, and wait and see. One point of view on the combination of the coping styles 'avoidance/waiting' and 'passive reaction pattern' is inspired by the fact that both of these scales correlate [10]. Both of the scales contain clear elements of inadequacy and a low self-image in the long term [10]. From another point of view, the coping style of the controls with a relatively high voice handicap might indicate less stereotypy and probably more adequate adaptation, compared to that of the teachers. This is underlined by the fact that the controls with a relatively high voice handicap scored higher than their teacher counterparts on the subscale 'avoidance/waiting'. This interpretation of controls, i.e. that they cope more adequately, is formulated in the light of the cascade model $[16,17]$. In the short term, avoidance or waiting could be effective, as this coping mode reduces biological and emotional tension [10]. When adapted management of voice problems is not present, the nonefficient active struggling (phase 1 of the cascade model) and nonrewarding search for help is not effective neither in problem solving nor in reduction of stress.

The teachers who reported a relatively high voice handicap scored higher on the scale of 'seeking for social support' than the general population. This is probably due to the fact that scores of teachers are significantly higher for 'seeking for social support' compared to the general population, irrespective of their voice handicap. A relatively lower level of education correlates with a lower mean score on 'seeking for social support'. Teachers are more inclined than the majority of the population to look for empathy, to entrust others with one's concerns, to seek comfort and to ask for help [10]. This particular mode of coping in the teachers' competence to cope is applied, in spite of a relatively severe voice handicap. Maybe the habitual application of this mode of coping prevents teachers from overt avoidance of their professional communi- cation situations. However, this combination of teachers' coping styles turns out to be nonadapted in handling voice problems. This combination prevents them from adequate interventions that should lead to effective problem solving in a distress-disvoicing circle [16]. Moreover, prevailing eustress-euvoicing over distress-disvoicing is hampered $[12,13]$. Inadequate coping may lead to a state of 'chronicity'. De Jong et al. [15] described 'chronicity' as maintaining the problems in a deadlocked situation and consequently sliding down into a chronic disease. They stressed that 'chronicity' is essentially different from 'chronic', which refers only to the duration of the disease.

\section{Conclusions}

Teachers with relatively high voice handicap scores cope overall with a passive reaction pattern and less with an active coping style. Their counterparts from the general population also showed a style of passive reactions as a coping approach and additionally a trend towards avoidance/waiting. Teachers in general tend to seek for social support. The combination of the coping modes of the teachers may lead to less optimal problem solving possibilities and consequently increased vulnerability, problems and less psychosomatic well-being. Including effective coping strategies in the curriculum of student teachers may contribute to their response when they experience voice problems during their teaching career. With a view to self-efficacy, adequate coping strategies need to be taught to teachers. This has consequences for training, coaching, diagnostic and treatment programs.

\footnotetext{
References $>_{1}$ Smith E, Lemke J, Taylor M, Kirchner HL, Hoffman H: Frequency of voice problems among teachers and other occupations. J Voice 1998;12:480-488.

2 Russell A, Oates J, Greenwood KM: Prevalence of voice problems in teachers. J Voice 1998;12:467-479.

3 Verdolini K, Ramig LO: Review: occupational risks for voice problems. Logoped Phoniatr Vocol 2001;26:37-46.

4 Vilkman E: Occupational safety and health aspects of voice and speech professions. Folia Phoniatr Logop 2004;56:220-253.

5 Yiu EML: Impact and prevention of voice problems in the teaching profession: embracing the consumers' view. J Voice 2002; 16:215-228.
} 
6 Williams NR: Occupational groups at risk of voice disorders: a review of the literature. Occup Med 2003;53:456-460.

7 Mattiske JA, Oates JM, Greenwood KM: Vocal problems among teachers: a review of prevalence, causes, prevention, and treatment. J Voice 1998;12:489-499.

$>8$ De Jong FICRS, Kooijman PGC, Thomas G, Huinck WJ, Graamans K: Epidemiology of voice problems in Dutch teachers. Folia Phoniatr Logop 2006;58:186-198.

9 Jacobson BH, Johnson A, Grywalski C, Silbergleit A, Jacobson G, Benninger MS, et al: The Voice Handicap Index (VHI): development and validation. Am J Speech Lang Pathol 1997;3:66-70.

10 Schreurs PJG, Van de Willege G: Omgaan met problemen en gebeurtenissen. De Utrechtse Coping-Lijst (UCL). Handleiding. Lisse, Swets en Zeitlinger, 1988.
11 Lazarus RS, Folkman S: Stress, Appraisal and Coping. New York, Springer, 1984.

12 Wellens WAR, Van Opstal MJMC: Performance stress in professional voice users; in Dejonckere PH (ed): Occupational Voice Care and Cure. The Hague, Kugler, 2001, pp 81-100.

13 Wellens WAR, Van Opstal MJMC: A comprehensive model of how the stress chain affects voice; in Izdebski K (ed): Emotion in the Human Voice. San Diego, Plural Publishing, 2008, vol 2, pp 253-271.
14 De Bodt M, Jacobson BH, Musschoot S, Zaman S, Heylen L, Mertens F, et al: De Voice Handicap Index. Een instrument voor het kwantificeren van de psychiosociale consequenties van stemstoornissen. Logopedie 2000;13:29-33.

15 de Jong FICRS, Cornelis BE, Wuyts FL, Kooijman PGC, Schutte HK, Oudes MJ, et al: A psychological cascade model for persisting voice problems in teachers. Folia Phoniatr Logop 2003;55:91-101.

16 Anderson DJ: The psychologic cascade; in White AH, Schofferman JA (eds): Spine Care. St Louis, Mosby, 1995, pp 36-44.

-17 Vanhoudt I, Thomas G, Wellens WAR, Vertommen $\mathrm{H}$, de Jong FICRS: The background biopsychosocial status of teachers with voice problems. J Psychosom Res 2008;65:371380. 